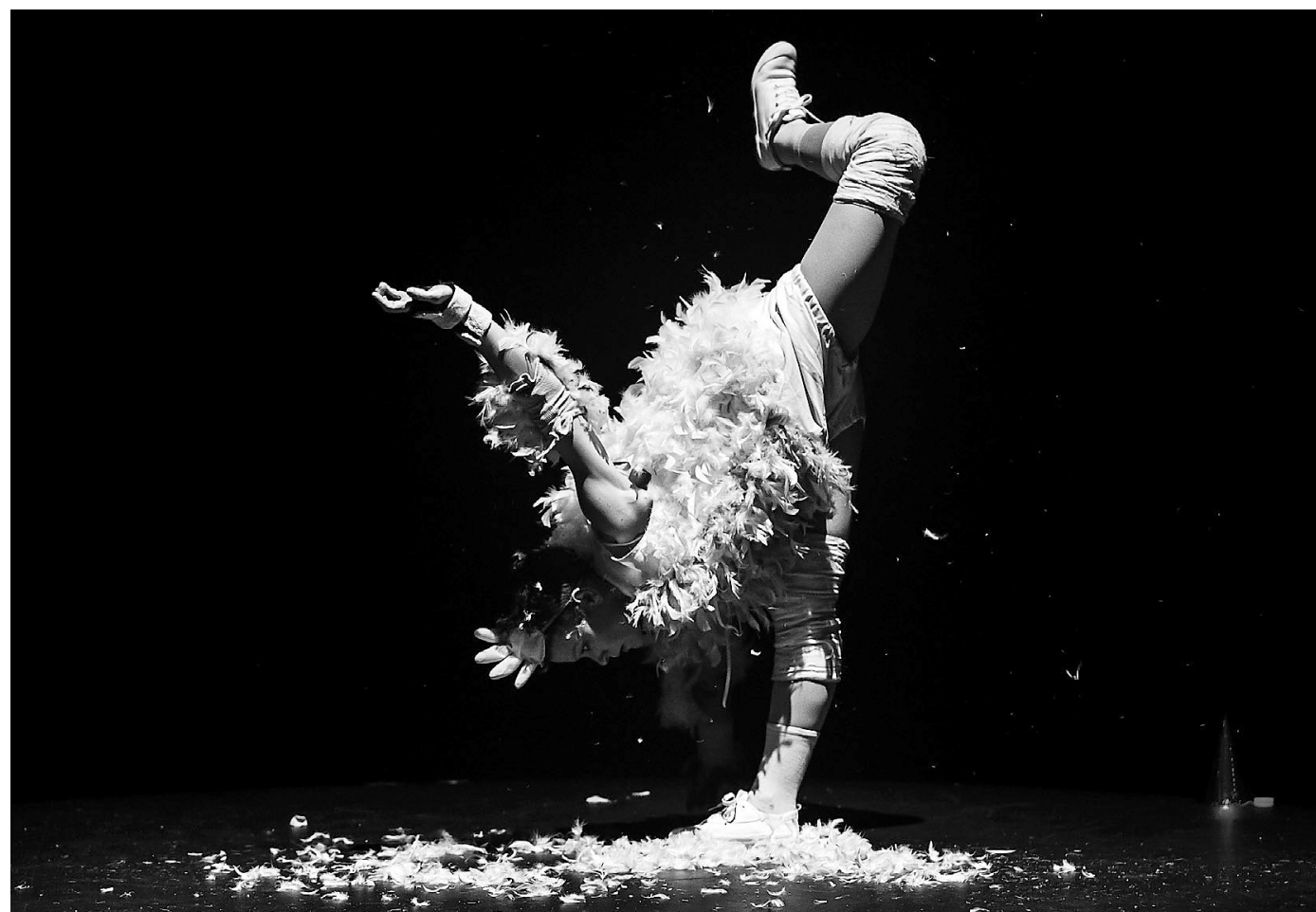

\title{
O novo circo em Edimburgo Areias movediças? Pecadilhos?
}

\section{Constança Carvalho Homem}

Há espectáculos de que é possível gostar tendo consciência do quanto destoam das nossas preferências mais marcadas ou imediatas. É uma estranha experiência de simultaneidade, a que provocam - de fruição e surpresa, de abandono e censura. A reflexão que tentarei fazer parte desta encruzilhada e aborda duas criações australianas, nomeadamente Fright or Flight, do recém-formado colectivo 3 is a Crowd, e Wunderkammer, da já reconhecida companhia Circa. Porque o exercício da crítica é também este, julgo eu: reflectir sobre as concessões que um espectador privilegiado vai fazendo, tentar perceber que proporção de originalidade e eficácia consegue evitar um dos grandes pilares da emissão de um juizo, a auto-imagem do gosto.

Mesmo se em perfeito contraste à superfície, julgo que importa reconhecer o que Fright or Flighte

Wunderkammer têm em comum, a começar pela posição intermédia que ocupam no espectro de possibilidades do circo contemporâneo. Estes espectáculos não assentam exclusivamente em fórmulas e aptidões convencionadas, mas também não se permitem rupturas relevantes, seja por inexperiência, seja por confronto com o mercado. Ainda assim, e de acordo com as suas respectivas escala e prudência, de ambos emerge uma modalidade de circo que não se resume a uma arena de proezas indiscutíveis, mas pode ser lugar onde o virtuosismo não se separa da singularidade. Talvez não espante que ambos prescindam de tenda e banda ao vivo - e se o refiro não penso tanto no esforço financeiro que estes elementos acarretam nem em constrangimentos à circulação; penso sobretudo na tenda como conotação e expectativa, e penso também nas muitas limitações artísticas que Ihe são inerentes. Creio, por isso, que a substituição de um formato de cariz popular, que pouco mistério encerra, bem como a atenção redobrada ao desenho de som e ao desenho de luz, concorrem para a produção de sentido; sugerem, se ainda não ousam percorrê-los, territórios mais delicados, instáveis, pessoais. Portanto, há indícios de um pensamento que condensa meta-circo e dramaturgia, e gostaria de o ter visto mais aprofundado.

Pensar uma forma artística que se conhece menos bem obriga a alguns parêntesis. Exporei um, enunciando uma pergunta: que riscos e promessas há para o circo quando se deixa permear ou já só empresta os seus códigos à carne e têmpera singular dos seus intérpretes? Diria que há risco significativo associado a um peso histórico, ao facto de podermos ser lembrados dos tempos em que circo e freakshow eram designações passiveis de confundirse, tempos em que muito dolorosas singularidades podiam ser a carta alta do empresário. Nesse sentido, quanto mais manifesta uma competência técnica mais o espectáculo se protege. 0 que é assinalável é ver que as promessas querem prescindir dessa protecção. Na verdade, elas vêm sendo cumpridas muito por força de artistas que talvez não saibamos classificar de forma precisa, cuja prática dilata as fronteiras do que entendemos como disciplinas e se distingue pela pesquisa, pela experimentação e, porque
Texto apresentado no

âmbito do projecto Unpack the Arts (programa de residências para jornalistas culturais europeus).

Constança Carvalho Homem

é doutoranda da

Faculdade de Letras da Universidade do Porto. A sua actividade profissional abrange a tradução para a cena, a dramaturgia, a interpetação e a criação. 
dir. Yaron Lifchitz, CIRCA

2010 (Alice Muntz) fot. Andy Phillipson.

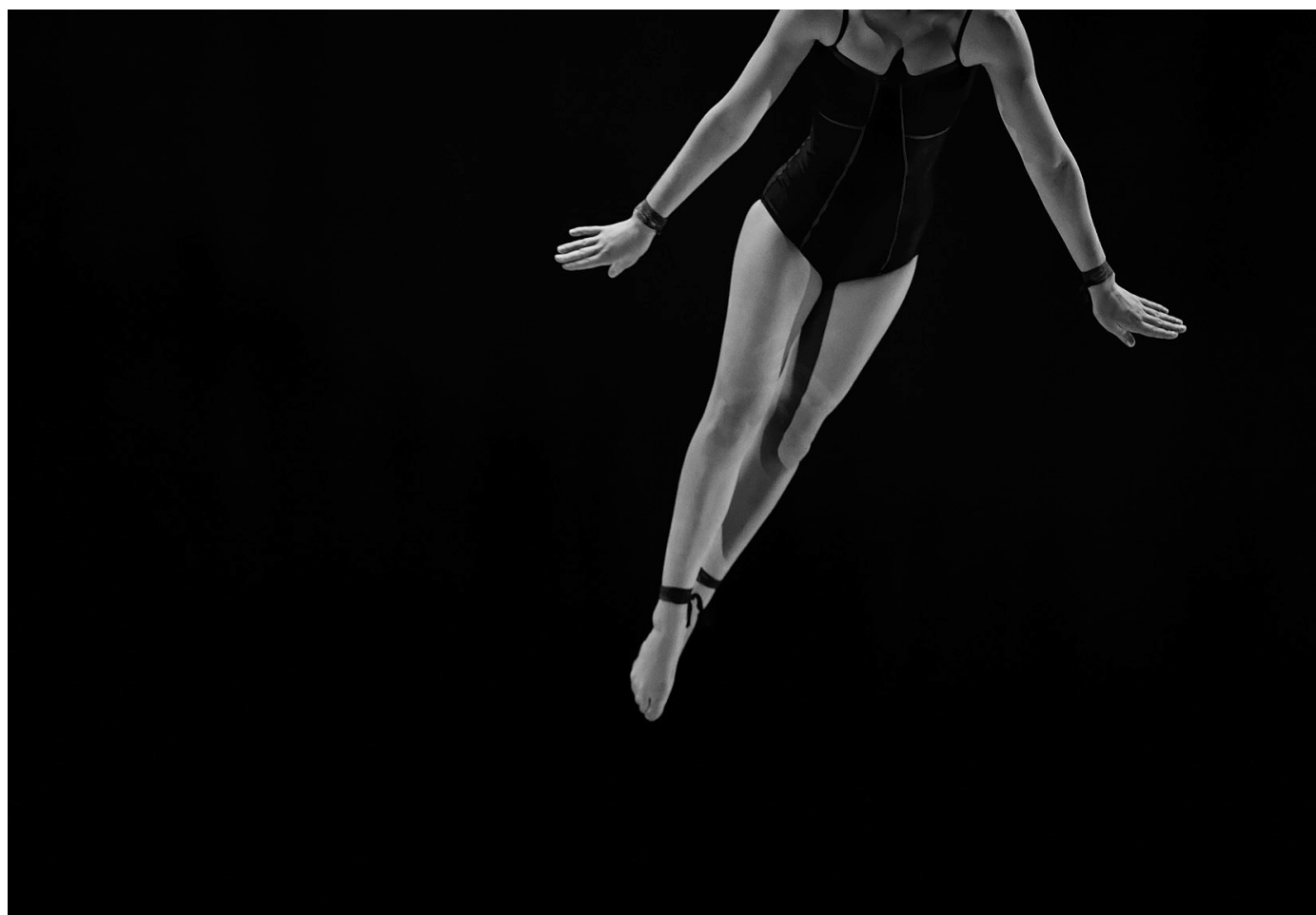

não dizê-lo, por alguma indulgência. Dois casos de promessa cumprida especialmente empolgantes são Éloge du poil, de Jeanne Mordoj, e P.P.P., de Phia Ménard, e se agora menciono estes espectáculos e não os que vieram a Edimburgo em 2013, faço-o de forma deliberada; de facto, parecem-me ser os melhores exemplos de digestão do tempo histórico e de tempos intimos, criações que proporcionam um justo diálogo entre a memória do bizarro do velho circo e a valorização de um percurso pessoal.

Criações como as que acabo de referir são possiveis na medida em que reflectem anos de labor, de curiosidade sobre o mundo e experiência de vida. Ora, Fright or Flight e Wunderkammer não podem competir a esse nivel e, no entanto, vejamos: têm maturidade bastante para não explorar a contemplação do aberrante ou do extraordinário per se, ainda que a espaços queiram parecer fazê-lo!; e são indulgentes o bastante para apresentar tanto a façanha como o fiasco programado, com espaço para uma execução personalizada. Então talvez deva falar de visibilidade e de identidade: à sua maneira, estas duas propostas concorrem para uma nova leitura de corpos sumamente especializados, protegidos habitualmente porque vistos em função. E esse expor do corpo-tomado-por-adquirido, esse ver do corpo para lá do utensílio, produz uma integralidade bem-vinda dá-nos a face múltipla de um conjunto de intérpretes que, educados numa prática atreita a estereótipos e especialidades, terá licença para transbordar. Por outro lado, ambos os espectáculos procuram baralhar o que à partida é distinto e discernivel; quando nivelam o gesto hábil e o gesto perfeitamente risível, o que nos mostram é uma modalidade de circo consciente dos efeitos que provoca, com vontade de eventualmente os desmontar e lançar sobre si uma mão cheia de auto-ironia.

Passemos a uma análise mais concreta, começando por Wunderkammer. A companhia Circa é repetente em Edimburgo e o espectáculo que traz, já com três anos de vida e um naipe de críticas entusiásticas, foi recebido com alvoroço. Em teoria, Wunderkammer seria um objecto compósito que funde acrobacia e burlesco, mas na prática o que primeiro senti foi que estava perante um esquema acrobático clássico com um invólucro fetichista. 0 espectáculo transpira a mecânica do evento diurno, tradicional. Do ponto de vista da estrutura, porque propõe um alinhamento de números independentes, mas também do ponto de vista da relação que pretende estabelecer com o público. Mesmo num anfiteatro de grande dimensão como é o McEwan Hall, o aplauso é incentivado por uma disposição coreográfica que habitualmente acaba em plano frontal e vénia.

Yaron Lifschitz, director artístico da companhia, diria em conversa que trabalhou a partir do conceito de fuga, que lhe interessava uma escrita polifónica ao invés da ideia única. Lamentavelmente, é notória a concessão a uma irreverência perfeitamente previsivel, o que torna o espectáculo refém de um jogo lúbrico fácil e porventura dispersivo. A versão apresentada no festival tem um corte de 20 minutos em relação ao original e, diz-nos quem viu a versão anterior, terá perdido certa subtileza. Porém, se tivermos em conta o marketing que acompanha o espectáculo, e a despeito das ambições eruditas que Yaron possa ter tido inicialmente, não é resultado deste corte a deriva comercial de Wunderkammer. Ela está contida na sua génese e no desejo, até certo ponto simplista, de celebração do corpo e da sensualidade. Concretizando com um termo de comparação, diria que enquanto produto Wunderkammer tem a batida, a atitude e a aparência expectáveis de um videoclip das Scissor Sisters. Com estas reservas, não esperava que o espectáculo me surpreendesse, mas efectivamente houve muitos momentos em que ced sem preconceito. Em primeiro lugar, o espantoso número de mastro chinês. A competência técnica dos dois intérpretes masculinos, o fluxo e refluxo de um tema de Ärvo Pärt, e o facto de não sermos distraídos por músculo visivel, criam a aparência de um diálogo tão leve que mal parece humano, 


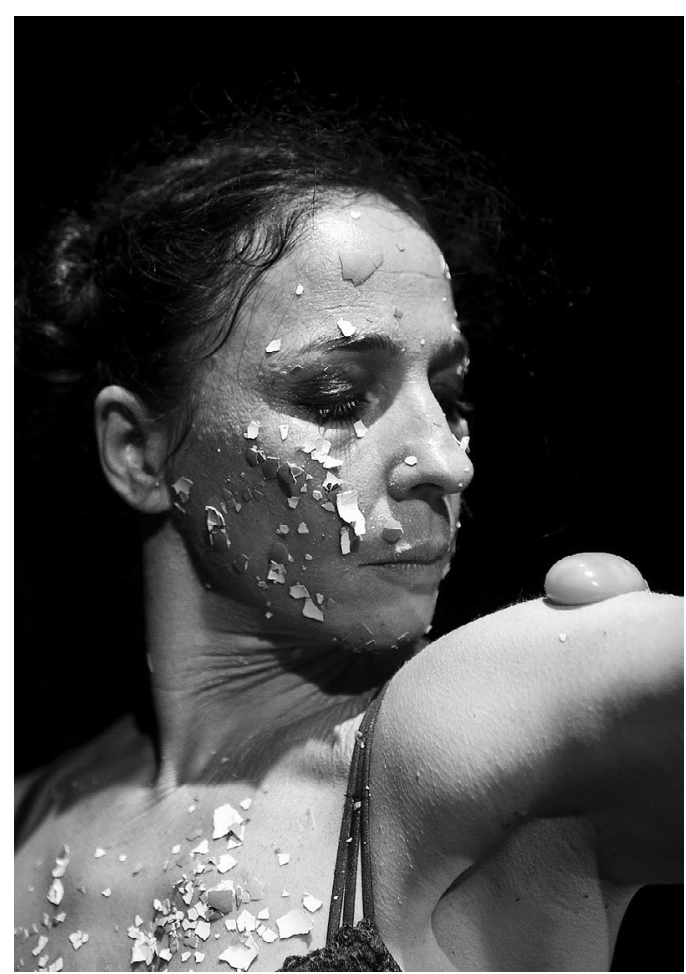

e tão próximo que resulta ambíguo. Não é possivel saberse se o que testemunhamos é uma conversa entre irmãos ou entre amantes, e pouco importa saber se falam ou dançam; o que transparece é a expressão muito delicada de um afecto universalmente reconhecido. Houve outros momentos em que a veia humoristica dominou com inteligência, aproveitando estereótipos, e o striptease em trapézio é exemplo de como nos tiram o tapete. Entre o voluntarismo do intérprete masculino, que parece congratular-se com o lugar de desejo a que foi remetido, e a paródia do striptease numa coreografia disparatada, mas executada sem mácula e de olhos nos olhos, somos embalados por um Peter Gabriel em verve amorosa. É patético, comovente, ambas as coisas? 0 número em que Alice Muntz apresenta o seu bailado em película de bolhas de plástico deixa-nos dúvidas da mesma ordem. A rapariga leve e ágil, confinada pelo seu biótipo ao toss the girl, tem um solo de pleno direito em que se mostra, afinal, inábil e clownesca. É nestes interstícios que Wunderkammer me parece muito bem conseguido, na gestão da ironia e da ambiguidade, na gestão entre o que é e o que aparenta ser. 0 final do espectáculo volta a pregar-nos uma partida: despidos, à espera, ao som de um refrão que repete um "it's alright", os intérpretes aparecem inteiros porque não vigiados, efeminados, másculos e musculados nem sempre de acordo com o seu género; mas justamente quando pensamos que toda a euforia se esvaiu, que há um refrear do artifício, surge um último grande gesto. Ah, ainda faltava voar uma saia...

Circunstancial e artisticamente, o caso de Fright or Flighté de facto bastante diferente - um colectivo emergente traz ao festival um espectáculo com algumas semanas de circulação, premiado pouco antes no Fringe de Adelaide. A simplicidade desta apresentação parece-me em tudo conforme aos propósitos das 3 is a Crowd. Na conversa que tiveram connosco, Rockie Stone tomou a dianteira e falou-nos de três amigas que, a viver entre Melbourne e Brisbane, quiseram juntar-se em torno de um
La Poème

de Jeanne Mordoj,

2010 (Jeanne Mordoj), fot. Eoin Carey. objecto que sentissem como seu. Rockie deixou transparece a alegria e a urgência de um trabalho físico criado por intérpretes que se admiram mutuamente, mas não separou essa dimensão da necessidade de expor um universo partilhado, no que ele possa conter de patetice, mágoa ou estranheza. Aceitamos este desejo de assunção e de autoria quando nos apercebemos de que Rockie, Bianca e Olivia passaram por inúmeras companhias; percebemos também apesar da relutância que parecem ter em admiti-lo, que para os jovens criadores australianos a Circa foi e é um importantíssimo empregador, quando não mesmo alma mater. Portanto, o atrevimento deste espectáculo tem algo que ver com a sua modéstia; ele não pretende ser consensual, não poderia sê-lo, quando as cabeças que o urdiram estão a afastar-se de uma fórmula testada e a integrar a(s) sua(s) diferença(s). É, por outro lado, um espectáculo que aproveita laços existentes para Ihes dar um nexo de cena. Reconhecemos relações de poder e de protagonismo e temos quase a sensação de que há personagens, mas quanto a mim o esforço maior e algo inaudito é o de mostrar o artista as himself. Talvez por isso thes tenha sido natural usar um jogo caseiro como abertura do espectáculo, essa espécie de cabra-cega que rapidamente distingue as diferentes personas.

0 espectáculo tem um denominador comum: o tema dos pássaros. É talvez um pouco pueril e já visto, e não pode resolver certos problemas de ritmo, mas acaba por ter utilidade dupla: esbate a transição entre números e transporta uma espécie de narrativa. De facto, mesmo que de forma não militante ou deliberada, Fright or Flight veicula um discurso queer e constrói momentos e imagens de empowerment fazendo uso dessa metáfora. A fragilidade destes corpos é medida pela necessidade de acumular, vestir e enfeitar por excesso. Quando Rockie se adorna até quase se travestir, quando Bianca se cobre de penas, há um sentido profundo nesta necessidade de equipamento; quando Bird Gerhl, de Antony and the Johnsons, acompanha uma suspensão, e Blackbird, dos Beatles, mostra que Olivia é uma malabarista bem capaz, sentimos que o lugar destas intérpretes é o de brilhar nos seus respectivos domínios sem esconder um eventual ADN de patinho feio. Também não faltam tiradas de humor a equilibrar estes momentos de comoção inesperada. 0 que dizer das acções miniaturais à volta de um pacote de batatas fritas, duas espectadoras em cena a roubar o foco à estrela destacada? 0 que dizer também da inclusão de um tema como Passarinhos a bailar no original alemão, a recordar o mau entretenimento televisivo ou as festas populares? É a oscilação quase permanente entre o talento e a ineficácia, a progressão e o anti-clímax, que torna o espectáculo tão refrescante. Reconhecem-se, nesta primeira criação, vontade e talento mais que válidos, mesmo se porventura o trabalho possa ser visto como um espectáculo de nicho. Mas creio ter tido um vislumbre do que possam ser novos voos, altos voos: o exponenciar do tecido original de cada intérprete, bem como uma maior congruência rítmica e dramatúrgica, poderão ser a via mais interessante. 